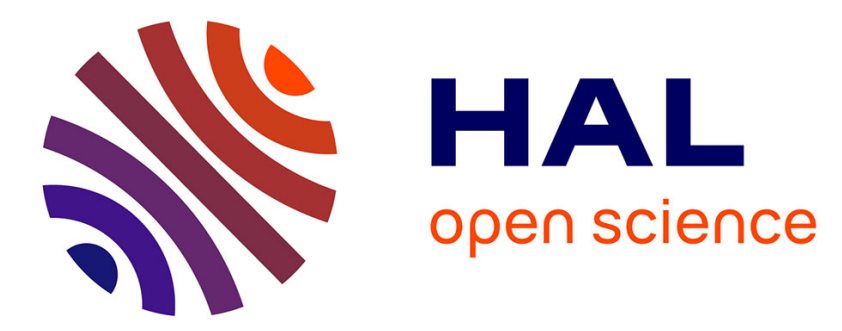

\title{
Nipple-sparing mastectomy: risk of nipple-areolar recurrences in a series of 579 cases
}

J. Y. Petit, U. Veronesi, P. Rey, N. Rotmensz, E. Botteri, M. Rietjens, C. Garusi, F. Lorenzi, S. Martella, R. Bosco, et al.

\section{- To cite this version:}

J. Y. Petit, U. Veronesi, P. Rey, N. Rotmensz, E. Botteri, et al.. Nipple-sparing mastectomy: risk of nipple-areolar recurrences in a series of 579 cases. Breast Cancer Research and Treatment, 2008, 114 (1), pp.97-101. 10.1007/s10549-008-9968-6 . hal-00478327

\section{HAL Id: hal-00478327 \\ https://hal.science/hal-00478327}

Submitted on 30 Apr 2010

HAL is a multi-disciplinary open access archive for the deposit and dissemination of scientific research documents, whether they are published or not. The documents may come from teaching and research institutions in France or abroad, or from public or private research centers.
L'archive ouverte pluridisciplinaire HAL, est destinée au dépôt et à la diffusion de documents scientifiques de niveau recherche, publiés ou non, émanant des établissements d'enseignement et de recherche français ou étrangers, des laboratoires publics ou privés. 


\title{
Nipple-sparing mastectomy: risk of nipple-areolar recurrences in a series of 579 cases
}

\author{
J. Y. Petit · U. Veronesi - P. Rey $\cdot$ N. Rotmensz $\cdot$ E. Botteri $\cdot$ M. Rietjens $\cdot$ \\ C. Garusi - F. De Lorenzi - S. Martella - R. Bosco - A. Manconi · \\ A. Luini $\cdot$ V. Galimberti $\cdot$ P. Veronesi $\cdot$ G. B. Ivaldi $\cdot$ R. Orecchia
}

Received: 3 March 2008/Accepted: 5 March 2008/Published online: 22 March 2008

(C) Springer Science+Business Media, LLC. 2008

\begin{abstract}
Background When the conservative treatment is not recommended, Nipple Sparing Mastectomy (NSM) is proposed more and more frequently for the surgical treatment of breast cancer. The risk of local recurrence behind the nipple areolar complex (NAC) is the main limiting factor of the NSM procedure. To minimize such risk, we proposed in 2002 a intraoperative radiotherapy of the preserved NAC. Patients and methods From March 2002 to November 2006, 579 cases (in 570 patients) of NSM were performed for carcinoma. The median follow up time was 19 months (Range: 1-60). The subcutaneous mastectomy was performed through an incision removing a portion of the skin overlying the tumour. An extemporaneous histological examination was performed on the retroareolar glandular tissue. If the histology was positive the patient was not considered eligible. Then an intraoperative radiotherapy with electrons (ELIOT) of 16 Gy in one shot was
\end{abstract}

J. Y. Petit $(\bowtie) \cdot$ P. Rey · M. Rietjens · C. Garusi ·

F. De Lorenzi - S. Martella - R. Bosco - A. Manconi

Department of Plastic Surgery, European Institute of Oncology,

Via Ripamonti 435, Milan 20 141, Italy

e-mail: jean.petit@ieo.it

\section{U. Veronesi}

Scientific Direction, European Institute of Oncology,

Milan, Italy

N. Rotmensz $\cdot$ E. Botteri

Division of Epidemiology and Biostatistics,

European Institute of Oncology, Milan, Italy

\section{A. Luini · V. Galimberti · P. Veronesi}

Department of Breast Surgery, European Institute of Oncology, Milan, Italy

G. B. Ivaldi · R. Orecchia

Department of Radiotherapy, European Institute of Oncology, Milan, Italy delivered on the NAC area. An immediate breast reconstruction was done using implants in most cases and in several cases a musculocutaneous flaps, usually in large breast. The number of local recurrences was recorded and the correlation between their occurrence and the clinical and histological criteria were analysed using the Gray test statistical method in a competing framework. Results In 516 cases the negative retroareolar frozen section biopsy was confirmed by the final histology, while in 63 cases, the final histology showed foci of carcinoma. Seven out of these 63 cases underwent a secondary NAC removal. In the 56 cases which preserved areolas we did not observe any local recurrence after 19 months follow up. The probability of retro areola positive histology increases with the tumour size. and was not related to the nodal status. The rate of local relapses was $0.9 \%$ per year. We didn't find any significant difference in the local relapse rate according to different patient's and tumour's features. Most relapses were located close to the tumour bed but never in the NAC area. Conclusion Our study confirms that the local recurrence rate in the NSM completed with local radiotherapy on the NAC is not higher than the usual rate observed in the literature and the preservation of the NAC does not increase the risk. The absence of local recurrence in the region where a portion of glandular tissue has been purposely preserved is a good argument in favour of ELIOT.

Keywords Nipple-sparing - Mastectomy - Breast . Conservative treatment

\section{Introduction}

Mastectomy is still required in around 20-25\% of breast cancer patients, especially in case of multicentric, large 
tumours or recurrences after conservative treatment. The feeling of mutilation is increased because of the removal of the nipple areola complex (NAC) and remains despite the psychological improvement due to the NAC reconstruction [1]. The NAC seems to be the signature of the breast identity more than the volume or the shape which can be changed easily in esthetic surgery.

For these reasons we proposed in 2002 a new mastectomy technique preserving the Nipple Areolar Complex: the Nipple Sparing Mastectomy (NSM) [2].

Since then we performed more than 700 NSM and we explore for the first time, in this paper, the oncological results of this type of intervention.

The most important risk of preserving NAC is retroareolar or areolar relapse. Number of articles studied the relation of nipple and areola involvement and the tumour site, the tumour size and the nodal status [3-8] but we didn't find in the literature data about the risk of retroareolar recurrence in relation with the conservation of the NAC in case of breast cancer treatment. Most of these studies concluded that the NAC could be preserved only in the case of small tumours located at a distance from the areola, and with negative axillary nodes.

Based on the results of intra-operative radiotherapy (ELIOT) studies [2, 9-14], we assumed that an intraoperative radiotherapy with electrons could avoid or decrease the risk of LR in selected patients with preserved NAC.

\section{Technique}

The surgical technique has been previously described in our pilot study [2]. We consider very important the subcutaneous dissection under the areola that should remove the maximum of glandular and ductal tissue without compromising the NAC vascularization. The specimen should be carefully marked especially in the retroareolar area to allow a precise localization of the tumour by the pathologist. The ducts beneath the areola are taken separately to be analysed by frozen section: in case of positive histology the NAC should be removed. In case of poor blood supply and high risk of final necrosis, the plastic surgeon can also decide to remove the NAC before the delivery of radiotherapy.

\section{ELIOT}

The technique of ELIOT has been described in breast conserving surgery $[10,11,14]$. A total dose of 16 Gy (at the point of maximum dose) is delivered in the region of the NAC. The biologic equivalent of a single intra-operative dose is felt to be 1.5-2.5 higher than the dose delivered with conventional fractionated irradiation. More precisely, equivalent doses can be estimated using radiobiological models to predict radiation effects. According to linearquadratic model and computing the surviving fraction of clonogenic units, a single dose of 16 Gy corresponds to a fractionated dose of about 45 Gy for early-responding tissue (tumour cells) and of 70-80 Gy for late-responding tissues (vessels, fat, nerves).

\section{Breast reconstruction}

The immediate breast reconstruction (IBR) was performed by a second team with different technique (expander, definitive prosthese or flap) depending on the size of the breast, the local situation, the possible contraindications and the wish of the patient.

\section{Patients and methods}

From March 2002 to January 2007, 810 patients were admitted at IEO with an indication of NSM.

Inclusion criteria were: multifocal and multicentric breast carcinoma, unicentric carcinoma not suitable to quadrantectomy for anatomic reasons, extensive intraductal neoplasia involving more than one quadrant.

Exclusion criteria were: tumours bigger than $3 \mathrm{~cm}$, clinical invasion of the NAC, tumours closer than $1 \mathrm{~cm}$ from the areola, positive retroareolar frozen section.

Eighty-seven patients were excluded because of a positive retroareolar frozen section ( 83 cases) or NAC with insufficient vascularization (4 cases).

Seven hundred and three NSM were performed (579 for invasive cancer and 124 for in-situ disease), in 678 patients, 25 patients had bilateral NSM, 21 synchronous and 4 metachronous (Table 1).

In 169 patients ELIOT was not performed either for technical problems or for a poor vascularization of the nipple.

In 124 patients (127 NSM) the radiotherapy was delayed to the following days and performed by external beam and 45 patients never had radiotherapy because of the local conditions (36 cases) or because of a previous breast irradiation (9 cases).

\section{Statistical methods}

Disease-free survival was calculated from date of surgery to any local, regional or distant relapse, whichever occurred first, or to last visit date in case of no events. Other primary tumours were considered as competing events. Loco-regional disease-free survival was calculated from 
Table 1 Patients selection for the study

\begin{tabular}{llll}
\hline & ELIOT of the nipple areola & External Radiotherapy & No Radiotherapy \\
\hline Nipple sparing mastectomy & & & \\
Patients & 554 & 124 & 45 \\
Interventions & 579 & 124 & 47 \\
RT dose & $16 \mathrm{~Gy}$ & $16 \mathrm{~Gy}$ & \\
Irradiated area: average & $14.4 \mathrm{~cm}^{2}$ & $18.6 \mathrm{~cm}^{2}$ & \\
Range & $7.07-38.5$ & $16-36$ & \\
Fractions & 1 & $1-2$ & \\
Delay in days: average & 0 & 2.5 & \\
& & $1-85$ & \\
& & $94 \% \leq 3$ & \\
\hline
\end{tabular}

date of surgery to any local or regional relapse or to last visit date in case of no events. Other primary tumours and distant relapses were considered as competing events. Gray test was used to compare survival across different subgroups [15]. All analyses were performed with the SAS software (SAS Institute, Cary, NC). All tests were two sided.

\section{Results}

Patients characteristics and outcome are summarised in Table 2. The evaluation of the relapses was made considering only the carcinomas excluding all cases of pure Ductal Intraepithelial Neoplasia (DIN) and the four cases of metachronous tumour. The rate of local relapses is $0.9 \%$ per year.

Most local relapses (6/8 cases) were in the primary tumour bed, and no one occurred in the radiotherapy field. One local relapse was located in the opposite quadrant and another one was on the chest wall below the clavicle.

All local regional events were treated by surgery and all patients are alive 7-34 months after the local relapse.

A full description of all events is given in Table 3: we observed 13 metastasis and 14 local or regional relapses. In addition we experienced three other primary tumours (one uterine cervix, one brain tumour and one renal cancer) and one breast cancer related death.

Cumulative incidence of any local, regional or distant relapse and overall survival curves are shown in Figs. 1 and 2 respectively.

In our study the rate of positive retroareolar histology increased with the dimension of the tumour and was $12.6 \%$ for pT $1,23.3 \%$ for pT2 and $36.8 \%$ in case of pT3. These differences are significant (all $P<0.0002$ ). We didn't find any significant difference for the nodal status: $7 \%$ of positive retroareolar histology in case of $\mathrm{pN} 0,12.5 \%$ in case of $\mathrm{pN} 1,12.1 \%$ for the $\mathrm{pN} 2$ and $8.3 \%$ in case of $\mathrm{pN} 3$.

According with our internal guidelines all cases with positive retroareolar frozen section ( 83 cases) were considered
Table 2 Patients characteristics and outcome

\begin{tabular}{llc}
\hline Variable & Classification & No. $(\%)$ \\
\hline All patients & & 579 \\
Age & $<35$ years & $78(13.5)$ \\
& $35-49$ years & $380(65.6)$ \\
& $\geq 50$ years & $121(20.9)$ \\
Size of tumour & pT1 & $284(49.8)$ \\
& pT2 & $240(42.1)$ \\
Multifocality/multicentricity & pT3 & $46(8.1)$ \\
& Present & $177(31.0)$ \\
Number of positive lymphnodes & Absent & $394(69.0)$ \\
& 0 & $249(43.0)$ \\
Histotype & $1-3$ & $227(39.2)$ \\
& $\geq 4$ & $103(17.8)$ \\
Krogesteron receptors & Ductal & $452(78.1)$ \\
Grading & Lobular & $66(11.4)$ \\
& Mixed & $23(4.0)$ \\
Vascular invasion & Other & $38(6.6)$ \\
& Positive & $473(82.0)$ \\
& Negative & $104(18.0)$ \\
& Positive & $402(69.8)$ \\
& Negative & $174(30.2)$ \\
& G1 & $66(12.7)$ \\
& G2 & $244(47.1)$ \\
& G3 & $208(40.2)$ \\
& Overexpressed & $139(24.1)$ \\
& Not overexpressed & $438(75.9)$ \\
& $<20 \%$ & $282(49.1)$ \\
& $\geq 20 \%$ & $292(50.9)$ \\
& Absent & $377(65.1)$ \\
& & $202(34.9)$ \\
& &
\end{tabular}

not eligible and were excluded form the study. However, in 63 cases with negative frozen-section histology the definitive histology was positive for carcinoma. Out of these 63 patients, 7 underwent a secondary ablation of the NAC, while in 56 the 
Table 3 Description of events

\begin{tabular}{lrl}
\hline Description of events & No. & Rate $\times 100$ patient years \\
\hline First event & & \\
Local & 8 & 0.9 \\
Regional & 5 & 0.6 \\
Loco-regional & 1 & 0.1 \\
Distant & 13 & 1.5 \\
Other primary tumour & 3 & 0.4 \\
Death & 1 & 0.2 \\
\hline
\end{tabular}

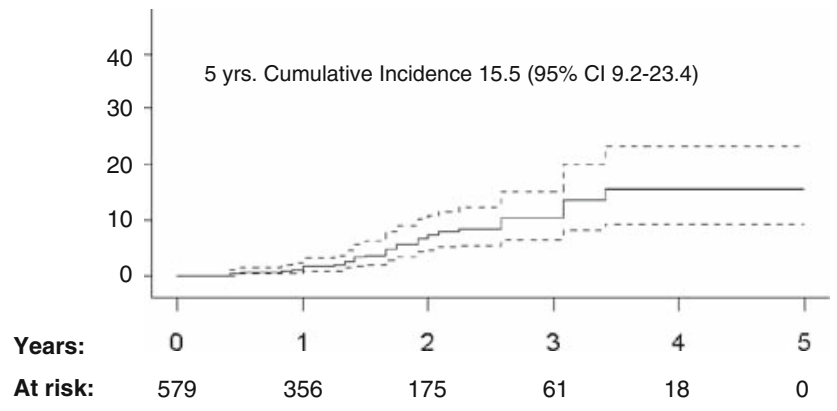

Fig. 1 Cumulative incidence of any local, regional or distant relapse. The events occurred between 6 and 41 months after the first intervention

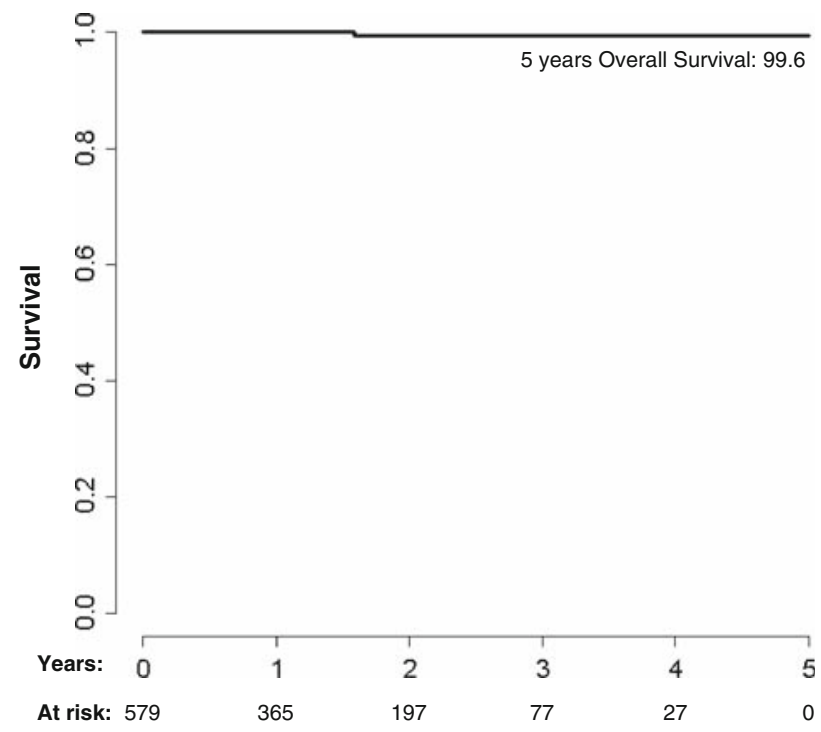

Fig. 2 Overall survival

NAC was saved. This decision was taken, after discussion with the patient, according to the hypothesis that radiotherapy would have destroyed any residual disease. In this series of 56 cases of conservation of the NAC (47 in situ lesions and 9 carcinomas) despite the final positive histology, we didn't experience any local relapse after 19 months of follow up.

\section{Discussion}

Our first concern, when we proposed the NSM [2], was to avoid the retroareolar local relapses. For this reason the mammary tissue left in the retroareolar region was the minimal compatible with the survival of the nipple complex. Moreover a frozen section histology was always taken in the retroareolar region to be certain of its integrity. With these precautions and with the irradiation of the areola with high energy electron we did not observe a single recurrence in the retroareolar area. The number of local recurrences observed in other sites was low (8) and is consistent with the rate of LR after modified mastectomies ( $1 \%$ per year). Most of them were close to the primary tumour site despite the skin resection performed over the tumour bed. We have no comparative data to conclude that the absence of retroareolar recurrences is due to the ELIOT. However, we should stress that out of 579 patients with negative extemporaneous retroareolar examinations, $63(10 \%)$ were positive at the final histology. The tumour was in situ in 51 cases $(81 \%)$ and invasive in 12 cases (19\%). Only 7 NAC were removed among the 63 positive, while 56 patients kept their NAC despite the positive histology. No recurrences were observed in the follow up of this group after 20 months. Gajdos et al. have already stressed the role of the radiotherapy to prevent the retroareolar recurrence [5]. The risk of retroareolar recurrence appears very low even when no radiotherapy is delivered $[3,7,8]$, therefore a randomized trial would not reveal any difference without a huge accrual of patients.

The nipple areolar invasion by the tumour cells is considered a major reason to avoid NAC conservation during mastectomy [16-19]. The relation between different preoperative parameters, and the presence of positive retroareolar histology is an important issue often underlined in the literature [20-22]. Most of these authors observe a relation between the tumour size, the tumour site, the lymph node metastases and the risk of retroareolar tumour involvement $[3,6,7]$. Our study does not confirm the relation between the retroareolar tumour invasion and lymph node metastases. In our series, the risk of retroareolar involvement increases with the tumour size as like in the majority of the studies in the literature. We agree that the site of the tumour can influence the risk of NAC involvement, and the limits generally accepted vary from 1 to $4 \mathrm{~cm}$ from the areola margins. Gajdos et al. [5] and Schecter include the mammogram to evaluate the distance between the tumour and the NAC. Schecter found an high rate $(42 \%)$ of nipple involvement in patients who underwent a total mastectomy, which is very different with our rate of $10 \%$. Friedmann et al. [23] made an interesting evaluation of the NAC invasion by MRI with an important diagnostic accuracy: In our series we didn't perform MRI as routine preoperative examination. Some authors proposed an histological 
retroareolar evaluation before the mastectomy: Palmieri et al. [24] by a surgical biopsy and Govindarajulu et al. [25] by a mammotome in place of the traditional frozen section. We didn't explore this possibility since we can have an histological response before the end of the mastectomy in order to decide the NAC conservation.

Finally we note that most of the articles in the literature are focused on the possibility to predict a retroareolar invasion before surgery in order to select the best cases for a NSM. Our results demonstrate a very low rate of events even without strict criteria for inclusion in the study.

\section{Conclusion}

Our study shows the absence of local recurrences in the areolar or retroareolar region where a small proportion of glandular tissue has been purposely preserved. Moreover it confirms that the local recurrence rate in the NSM, completed with local radiotherapy on the NAC, is not higher than the usual rate observed in the modified mastectomy, as reported in the literature.

\section{References}

1. Wellisch DK, Schain WS, Noone RB, Little JW 3rd (1987) The psychological contribution of nipple addition in breast reconstruction. Plast Reconstr Surg 80(5):699-704

2. Petit JY, Veronesi U, Orecchia R, Luini A, Rey P, Didier F, Giraldo A, Luini A, De Lorenzi F, Rietjens M, Garusi C, Intra M, Yamaguchi S, Martella S (2003) The nipple sparing mastectomy: early results of a feasability study of a new application of perioperative radiotherapy (ELIOT) in the treatment of breast cancer when mastectomy is indicated. Tumori 89:288-291

3. Cense HA, Rutgers EJ, Lopes-Cardozo M, Van Lanschot JJ (2001) Nipple sparing mastectomy in breast cancer: a viable option? Eur J Surg Oncol 6:521-526

4. Lambert PA, Kolm P, Perry RR (2000) Parameters that predict nipple involvement in breast cancer. J Am Coll Surg 191(4):354-359

5. Gajdos C, Tartter PI, Bleiweiss IJ (2000) Subareolar breast cancers. Am J Surg 180(3):167-170

6. Vyas JJ, Chinoy RF, Vaidya JS (1998) Prediction of nipple and areola involvement in breast cancer. Eur J Surg Oncol 24(1):15-16

7. Laronga C, Kemp B, Johnston D, Robb GL, Singletary SE (1999) The incidence of occult nipple-areola complex involvement in breast cancer patients receiving a skin sparing mastectomy. Ann Surg Oncol 6(6):609-613

8. Gerber B, Krause A, Reimer T et al (2003) Skin-sparing mastectomy with conservation of the nipple-areola complex and autologous reconstruction is an oncologically safe procedure. Ann Surg 238(1):120-127
9. Merrick HW, Battle JA, Padgett BJ, Dobelbower RR (1997) IORT for early breast cancer: a report on long-term results. Front Radiat Ther Oncol 31:126-130

10. DuBois J-B, Hay M, Gely S, Saint-Aubert B, Rouanet P, Pujol H (1997) IORT in breast carcinomas. Front Radiat Ther Oncol 31:131-137

11. Battle JA, DuBois J-B, Merrick HW, Dobelbower RR (1999) IORT for breast cancer. In: Gunderson LL et al (eds) Current clinical oncology: intraoperative irradiation: techniques and results. Humana Press Inc., New York, pp 521-526

12. Veronesi U, Orecchia R, Luini A, Gatti G, Intra M, Zurrida S, Ivaldi G, Tosi G, Ciocca M, Tosoni A, De Lucia F (2001) A preliminary report of intraoperative radiotherapy (IORT) in limited-stage breast cancers that are conservatively treated. Eur J Cancer 37:2178-2183

13. Veronesi U, Orecchia R, Luini A, Galimberti V, Gatti G, Intra M, Veronesi P, Leonardi MC, Ciocca M, Lazzari R, Caldarella P, Simsek S, Santos Silva L, Sances D (2005) Full-dose intraoperative radiotherapy with electrons durign breast conserving surgery. Experience with 590 cases. Ann Surg 242:101-106

14. Veronesi U, Orecchia R, Luini A, Gatti G, Intra M, Veronesi P et al (2001) Focalised intraoperative irradiation after conservative surgery for early stage breast cancer. Breast 10(Supplement3):84-89

15. Gray RJ (1988) A class of k-sample tests for comparing the cumulative incidence of a competing risk. Ann Stat 16:1141-1154

16. Smith J, Payne WS, Carney JA (1976) Involvement of the nipple and areola in carcinoma of the breast. Surg Gynecol Obstet 143(4):546-548

17. Andersen JA, Pallesen RM (1979) Spread to the nipple and areola in carcinoma of the breast. Ann Surg 189(3):367-372

18. Cucin RL, Guthrie RH Jr, Luterman A, Gray G, Goulian D Jr (1980) Screening the nipple for involvement in breast cancer. Ann Plast Surg 5(6):477-479

19. Andersen JA, Gram JB, Pallesen RM (1981) Involvement of the nipple and areola in breast cancer. Value of clinical findings. Scand J Plast Reconstr Surg 15(1):39-42

20. Schecter AK, Freeman MB, Giri D, Sabo E, Weinzweig J (2006) Applicability of the nipple-areola complex-sparing mastectomy: a prediction model using mammography to estimate risk of nippleareola complex involvement in breast cancer patients. Ann Plast Surg 56(5):498-504, discussion 504

21. Vlajcic Z, Zic R, Stanec S, Lambasa S, Petrovecki M, Stanec Z (2005) Nipple-areola complex preservation: predictive factors of neoplastic nipple-areola complex invasion. Ann Plast Surg 55(3):240-244

22. Lambert PA, Kolm P, Perry RR (2000) Parameters that predict nipple involvement in breast cancer. J Am Coll Surg 191(4):354-359

23. Friedman EP, Hall-Craggs MA, Mumtaz H, Schneidau A (1997) Breast MR and the appearance of the normal and abnormal nipple. Clin Radiol 52(11):854-861

24. Palmieri B, Baitchev G, Grappolini S, Costa A, Benuzzi G (2005) Delayed nipple-sparing modified subcutaneous mastectomy: rationale and technique. Breast J 11(3):173-178

25. Govindarajulu S, Narreddy S, Shere MH, Ibrahim NB, Sahu AK, Cawthorn SJ (2006) Preoperative mammotome biopsy of ducts beneath the nipple areola complex. Eur J Surg Oncol 32(4):410-412 